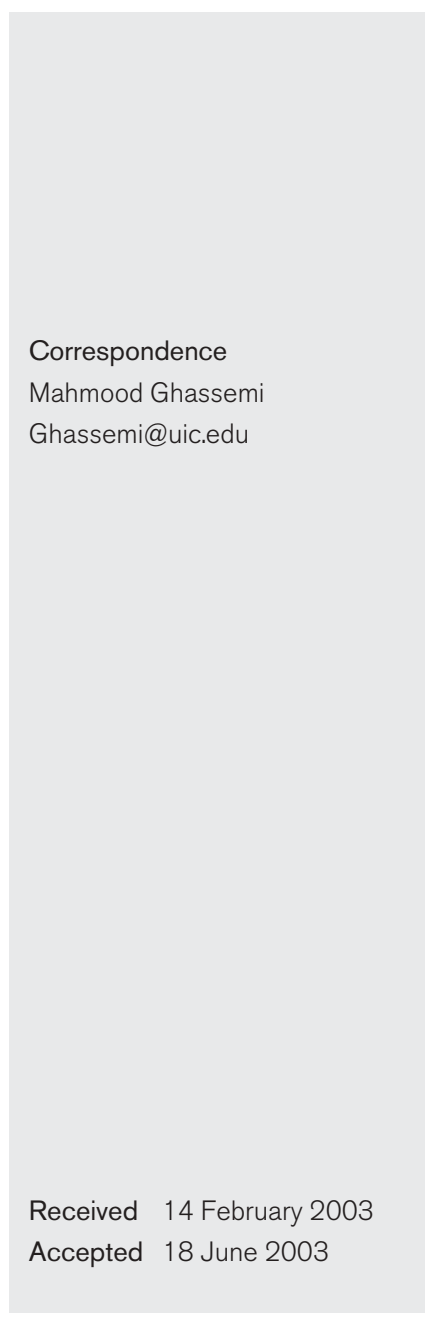

\title{
Viable Mycobacterium avium is required for the majority of human immunodeficiency virus-induced upregulation in monocytoid cells
}

\author{
Mahmood Ghassemi, Richard M. Novak, Mohammad F. Khalili and Jian Zhou \\ Department of Medicine, University of Illinois, 808 S. Wood St, Chicago, IL 60612, USA
}

\begin{abstract}
The Mycobacterium avium complex (MAC), an intracellular pathogen of cells of the macrophage lineage, often clinically coexists with human immunodeficiency virus type 1 (HIV). It was shown previously that coinfection of the monocytoid cell line U937 with HIV and MAC results in the enhancement of HIV replication. To determine whether MAC-mediated HIV upregulation is due to the exposure of intact organisms to HIV-infected cells or if actual infection with viable organisms is required for the effect, U937 cells were coinfected simultaneously with HIV and live or heat-killed MAC. Live MAC (infection) consistently increased HIV reverse transcriptase (RT) activity by more than 3-fold. Heat-killed MAC, however, failed to enhance RT activity significantly. Further investigation showed that infection of U38 cells [a U937-derived cell line containing regions of the HIV-1 long terminal repeat (LTR) linked to chloramphenicol acetyl transferase (CAT)] with live or heat-killed MAC resulted in a similar enhancement of HIV LTR-CAT transcription. In addition, transient transfection of U937 cells with a full-length wild-type HIV LTR-CAT construct revealed that heat-killed MAC stimulated LTR-mediated CAT activity to levels comparable to those of viable MAC. Finally, both live and heat-killed MAC mediated similar enhancement of NF- $\kappa B$ DNA-binding activity. Taken together, these observations confirm previous findings that MAC-induced NF- $\kappa$ B-dependent LTR-CAT activity is not a major factor in upregulating HIV expression in a coinfection model. It also indicates that MAC infection plays a significant role in the enhancement of HIV replication and suggests that viable MAC either contains or induces the production of an as-yet-unidentified factor(s) that mediates the enhancement of HIV replication.
\end{abstract}

\section{INTRODUCTION}

Several clinical, epidemiological and experimental studies have established a significant role for Mycobacterium avium complex (MAC) infection in the pathogenesis of human immunodeficiency virus type 1 (HIV). Data from in vitro and in vivo studies support the notion that MAC mediates the enhancement of HIV replication (Denis \& Ghadirian, 1994; Ghassemi et al., 1995; Orenstein et al., 1997; Wahl et al., 1998, 1999, 2000; Dezzutti et al., 1999). It is clear that the therapy for MAC infection in patients with AIDS lowers HIV replication, improves the quality of life and increases longevity in these individuals (Chin et al., 1994; Horsburgh et al., 1994).

MAC is widespread in nature and is the most common bacterial opportunistic infection in HIV-infected persons. The difference in infectivity, growth patterns and immunological responsiveness to MAC affects the ability of these

Abbreviations: MAC, Mycobacterium avium complex; HIV, human immunodeficiency virus; LTR, long terminal repeat; CAT, chloramphenicol acetyl transferase; RT, reverse transcriptase. organisms to multiply and survive within the host, and these characteristics are the determinants of pathogenicity in various clinical MAC isolates (Benson, 1994).

Using a coinfection model, we have reported previously that MAC increases HIV infection by increasing both the rate and the degree of replication (Ghassemi et al., 1995). Further investigation revealed that MAC-induced cytokine expression increases the formation of the cellular transcription factor NF- $\kappa \mathrm{B}$ (Ghassemi et al., 1999), which, in turn, enhances HIV-1 LTR-CAT [long terminal repeat (LTR) linked to chloramphenicol acetyl transferase (CAT)] transcription (Ghassemi et al., 2000). To assess whether the effect of MAC on HIV replication lies in the exposure of intact organisms to HIV-infected cells, thereby inducing the replication machinery of HIV, or, alternatively, the multiplication of MAC (i.e. MAC infection) is required for MACinduced HIV upregulation, we conducted a comparative analysis of the effect of viable as well as heat-killed MAC on HIV replication. We present data showing that heat-killed MAC fails to significantly increase HIV reverse transcriptase 
(RT) activity, despite the observation that both viable and heat-killed MAC induce comparable levels of HIV LTR-CAT expression and NF- $\kappa$ B DNA-binding activity.

\section{METHODS}

Cells. The human macrophage-like cell line U937 was obtained from the ATCC. The U38 cell line was obtained from the AIDS Research and Reference Reagent Program (contributed by Barbara Felber), National Institute of Health, Manassas, VA, USA. The U38 cell line is a U937derived cell line that contains the HIV-1 LTR promoter linked to the CAT gene and is a very sensitive indicator of the HIV-1 transactivating protein Tat (Felber \& Pavlakis, 1988). All cell lines were maintained in RPMI 1640 medium supplemented with $10 \mathrm{mM}$ HEPES, $2 \mathrm{mM}$ glutamine, $1 \mathrm{mM}$ sodium pyruvate (all materials from Mediatech) and $10 \%$ FBS (Sigma). Prior to each experiment, viability was checked routinely using the trypan blue dye-exclusion method. Cells were found to be negative for Mycoplasma contamination, as determined using a commercial kit (Gen-Probe) capable of detecting a broad range of Mycoplasma serotypes. The CEM.NKR-CCR5-Luc cell line, obtained from the AIDS Research and Reference Reagent Program (contributed by John Moore and Catherine Spenlehauer), was used for infectivity assays. This cell line expresses both CCR5 and CXCR4 coreceptors and is, therefore, permissive for a wide range of phenotypically distinct HIV1 isolates (Spenlehauer et al., 2001).

MAC isolates and virus strains. HIV- 1 strain RF, obtained from the AIDS Research and Reference Reagent Program (contributed by Robert Gallo), and MAC strain 101, serotype 1, an isolate from an AIDS patient, were used for this study. MAC and HIV stocks were prepared as described previously (Ghassemi et al., 1995). For the treatment of cells with MAC, each time an aliquot was thawed, it was washed with PBS and the pellet was resuspended in medium. The MAC suspension was then vortexed vigorously and divided into two microfuge tubes in identical volumes. To prepare the heat-killed MAC suspension, one tube was treated in a boiling water bath $\left(100{ }^{\circ} \mathrm{C}\right)$ for $30 \mathrm{~min}$.

Infection of cells with HIV and/or MAC. The cell suspension, at a concentration of $1 \times 10^{6} \mathrm{cells} \mathrm{ml}^{-1}$, was infected at $37^{\circ} \mathrm{C}$ for $2 \mathrm{~h}$ either with HIV or simultaneously with HIV and MAC, as described previously (Ghassemi et al., 1995). The cells were then washed with PBS and adjusted to $2 \times 10^{5} \mathrm{cells} \mathrm{ml}^{-1}$ (for assessment of the effect of MAC on HIV replication) or $1 \times 10^{6}$ cells $\mathrm{ml}^{-1}$ (for transfection or DNA-binding studies). All experiments were performed at least twice.

Virus infectivity assay. Culture supernatant ( $125 \mu \mathrm{l})$ from cell cultures containing cells infected with HIV alone (control) or simultaneously coinfected with HIV and MAC at the indicated days post-infection was added to CEM.NKR-CCR5-Luc cells (at a concentration of $2 \times 10^{5}$ cells per well in a 48 -well plate). The plate was then incubated at $37^{\circ} \mathrm{C}$ for 4 days. Cells were harvested, lysed and assayed for luciferase activity as described previously (Spenlehauer et al., 2001).

RT assay. The RT assay was performed as described previously (Lee et al., 1987). Briefly, HIV culture supernatant was lysed with dissociation buffer before adding a solution containing Tris, $\mathrm{KCl}, \mathrm{DTT}, \mathrm{MgCl}_{2}$, Triton X-100, template primer [poly $(\mathrm{rA}) \mathrm{p}(\mathrm{dT})]$ (Pharmacia) and $\left[{ }^{3} \mathrm{H}\right]$ TTP (Amersham). Samples were incubated overnight at $37^{\circ} \mathrm{C}$, after which $20 \%$ TCA supplemented with $0.02 \%$ sodium pyrophosphate was added. Samples were harvested on a cell harvester (model 200A; Cambridge Technologies) using $5 \%$ TCA, dried and counted in a scintillation counter. Results are reported as c.p.m.

Transfection studies. U38 cells $\left(1-2 \times 10^{7}\right)$ were treated with either serum-free RPMI medium or concurrently infected/treated with HIV and viable, or heat-killed, MAC for $2 \mathrm{~h}$, as described (Ghassemi et al., 2000). At $48 \mathrm{~h}$ post-treatment, cells were harvested and analysed for CAT activity.

Transient transfection of U937 cells with LTR-CAT DNA (Nabel \& Baltimore, 1987) was performed using the DEAE-dextran method, as described by Ghassemi et al. (2000). Transfected cells were incubated for $6-8 \mathrm{~h}$ at $37^{\circ} \mathrm{C}$ and subsequently divided into three aliquots: one aliquot was treated with medium (unstimulated) and the others were treated with either viable or heat-killed MAC for $2 \mathrm{~h}$ at $37^{\circ} \mathrm{C}$. Cells were then washed, counted and cultured in a $37^{\circ} \mathrm{C}$ incubator. Samples were taken $48 \mathrm{~h}$ later. Cell extracts were prepared by four freeze-thaw cycles and protein extracts were analysed by the CAT assay (Seed \& Sheen, 1988), as described previously (Ghassemi et al., 2000).

Analysis of DNA-binding proteins. To determine the induction of cellular transcription factor NF- $\kappa$ B activity by MAC, U937 cells were treated with RPMI medium, heat-killed MAC or viable MAC at $37{ }^{\circ} \mathrm{C}$ for $2 \mathrm{~h}$, shown previously to be the optimum condition for the induction of this transcription factor by MAC (Ghassemi et al., 1999). Nuclear extracts from uninfected and MAC-infected/treated cells were prepared using the method described by Schreiber et al. (1989) and assessed for DNA-binding activity using electrophoretic mobility shift assays, as described previously (Ghassemi et al., 1999).

\section{RESULTS}

\section{Effect of live or heat-killed MAC on HIV replication}

We have reported previously the enhancing effect of MAC on HIV replication in a coinfection model (Ghassemi et al., 1995). To compare the effect of live or heat-killed MAC on HIV replication in coculture, U937 cells were infected with HIV in the presence or absence of the same concentration of viable or heat-killed MAC, and HIV replication was monitored using an HIV-1 RT assay. Viable MAC (infection) consistently increased HIV RT activity by more than 3 -fold. Heat-killed MAC, however, failed to significantly enhance RT activity (Fig. 1), indicating that HIV upregulation appears to require viable MAC organisms. Using HIV-1 strain IIIB in combination with live or heat-killed MAC serotype 101 resulted in similar results (data not shown). We have reported previously that the MAC effect on HIV-1 replication is not HIV-1 or MAC strain dependent (Ghassemi et al., 1995).

To assess the enhanced HIV RT activity observed by viable MAC in a more physiologically relevant system, an infectivity assay was carried out. To this end, culture supernatant from the above experiment was added to CEM.NKR-CCR5-Luc cells and HIV-mediated LTR activation was measured using a luciferase assay. Culture supernatants from cells coinfected with HIV and viable MAC resulted in significant enhancement of LTR-driven luciferase production (Fig. 2). This observation, together with enhanced RT activity, confirms a significant increase in the production of infectious virus by viable MAC but not by heat-killed MAC.

\section{Induction of HIV LTR-CAT activity by live or heat- killed MAC}

In our previous study, we have shown that MAC infection 


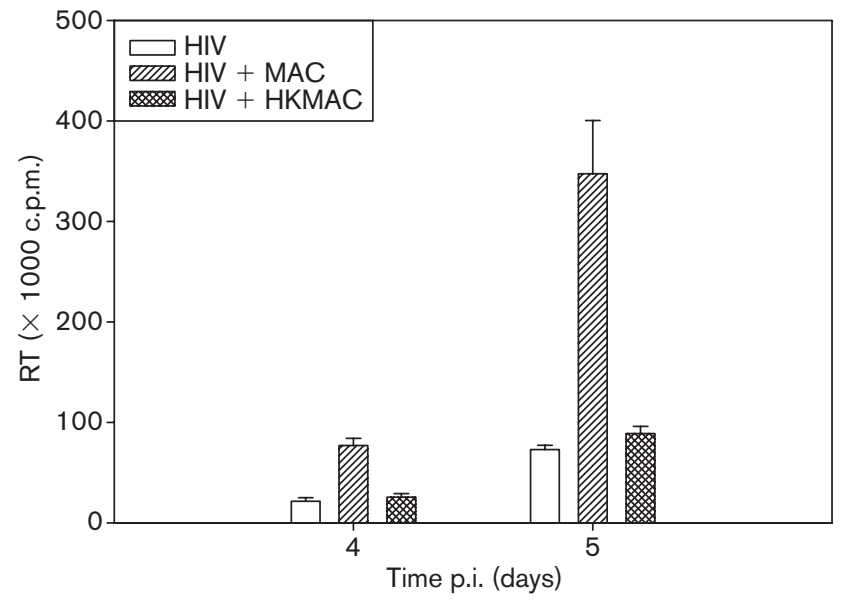

Fig. 1. Effect of viable and heat-killed MAC on HIV replication in coculture. U937 cells were infected with HIV in the presence or absence of an equal concentration of viable or heat-killed MAC for $2 \mathrm{~h}$ at $37^{\circ} \mathrm{C}$. Cells were then washed and incubated for the times indicated. HIV expression was monitored by RT assay. The data shown are the means \pm SD of a representative experiment.

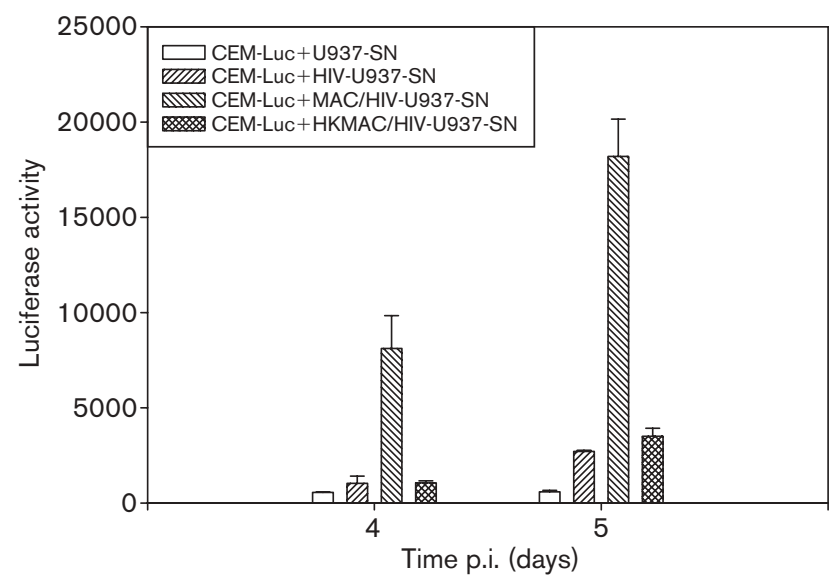

Fig. 2. Infectivity of (SN) virus produced by viable and heat-killed MAC. Culture supernatant at the time indicated from the above experiment was added to CEM.NKR-CCR5-Luc cells (CEM-Luc). Cells were harvested 4 days later and assayed for HIV-mediated LTRdriven luciferase activity. The data shown are the means \pm SD of a representative experiment.

induces HIV LTR-CAT activity. To examine the induction of HIV LTR promoter activity by heat-killed MAC relative to viable MAC, U38 cells, a subclone of the U937 cell line containing regions of the HIV-1 LTR linked to CAT, were infected/treated with HIV, viable MAC, heat-killed MAC or concurrently with both HIV and MAC, and HIV gene expression was monitored by CAT assay. As shown in Fig. 3, heat-killed MAC, at a concentration identical to viable MAC, induced CAT expression to a similar level as viable MAC.

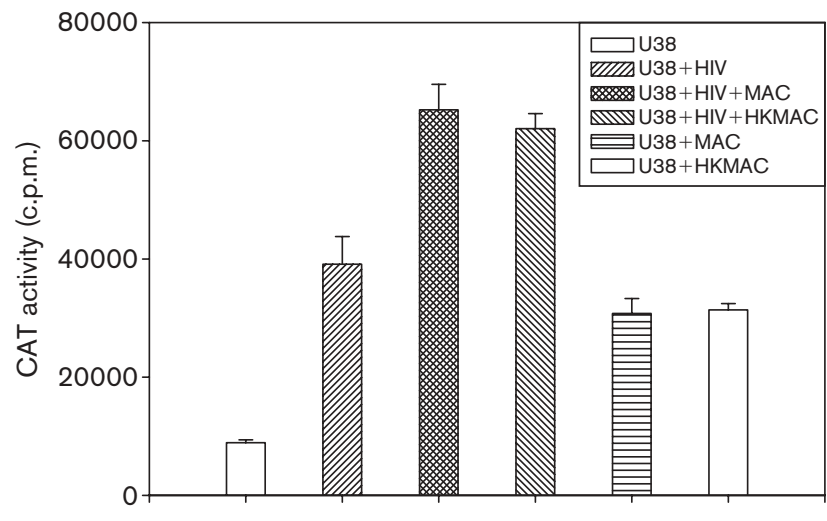

Fig. 3. HIV LTR-CAT expression by viable and heat-killed MAC in U38 cells. Cells were infected/treated with HIV, viable MAC or heatkilled MAC or simultaneously with HIV and either viable or heat-killed MAC for $2 \mathrm{~h}$ at $37^{\circ} \mathrm{C}$ and, after washing, incubated for a further $48 \mathrm{~h}$. CAT assays were performed using equivalent amounts of protein extract. Results are reported as c.p.m. Untreated U38 cells served as negative controls. The data are the means $\pm \mathrm{SD}$ of a representative experiment.

To confirm further the effect of MAC on HIV-1 LTRdirected transcription, a construct containing a full-length wild-type genome with an intact NF- $\kappa$ B-binding site, HIV-1 LTR-CAT was transiently transfected into U937 cells. Transfected cells were then treated with either viable or heat-killed MAC (in the presence or absence of HIV). As shown in Fig. 4, both viable and heat-killed MAC stimulated LTR-mediated CAT activity to comparable levels. The MAC-induced enhancement of promoter activity could not be detected in cells transfected with an HIV-1 LTR-CAT containing a deletion of the NF- $\kappa$ B-binding site unless cells were cotransfected with a Tat expression vector (Ghassemi et al., 2000).

\section{Induction of NF- $\kappa$ B-like proteins by MAC}

We have shown previously that viable MAC induces the formation of the nuclear NF- $\kappa$ B complex in U937 cells (Ghassemi et al., 1999). To determine whether heat-killed MAC induces changes in cellular transcription factor NF- $\kappa \mathrm{B}$ activity, U937 cells were left untreated (control) or treated with viable or heat-killed MAC and the extracts analysed for NF- $\kappa$ B DNA-binding activity. Fig. 5 shows that viable and heat-killed MAC increased NF- $\kappa$ B-binding activity to comparable levels. Infection of cells with HIV did not increase the formation of the nuclear NF- $\kappa \mathrm{B}$ complex significantly and simultaneous coinfection of cells with both HIV and MAC resulted in NF- $\kappa \mathrm{B}$ DNA-binding activity similar to that induced by MAC alone (data not shown).

\section{DISCUSSION}

MAC is among the most common opportunistic pathogen encountered in patients with advanced HIV infection (Benson, 1994). We have reported previously that MAC enhances HIV infection by increasing both the rate and the 


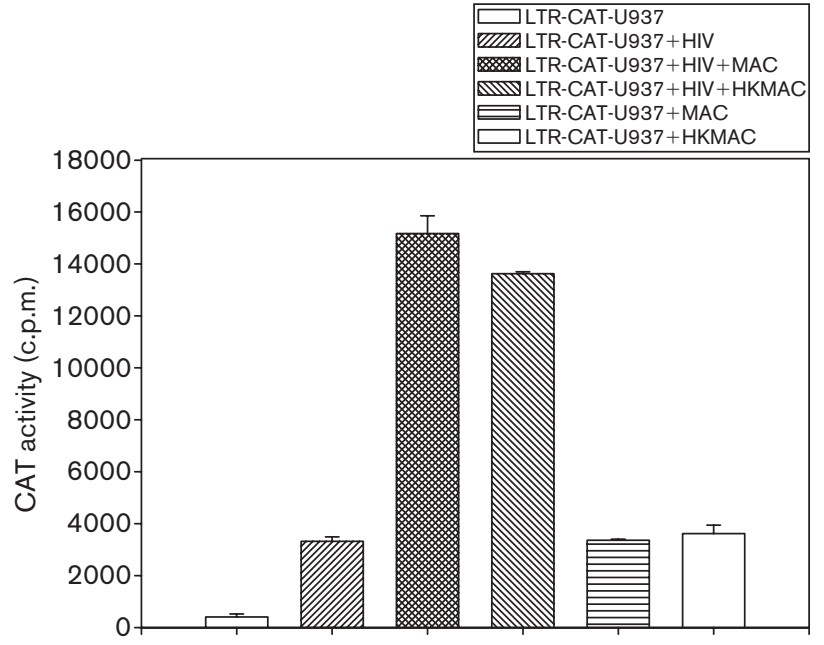

Fig. 4. Effect of viable or heat-killed MAC on HIV-1 LTR promoter activity. U937 cells were transiently transfected with the wild-type LTR-CAT construct and subsequently infected/treated with HIV, viable MAC or heat-killed MAC or simultaneously with HIV and either viable or heat-killed MAC. Cell extracts were analysed for CAT activity $48 \mathrm{~h}$ later. LTR-directed CAT activity is expressed as c.p.m. Untreated transfected cells (LTR-CAT-U937) served as negative controls. The data shown are the means \pm SD of a representative experiment.

degree of HIV replication in U937 cells (Ghassemi et al., 1995). We have shown further that MAC induced the activation of the cellular transcription factor NF- $\kappa \mathrm{B}$ (Ghassemi et al., 1999) and that MAC infection could stimulate NF- $\kappa \mathrm{B}$-dependent LTR-mediated CAT activity in U937 cells transfected with a wild-type LTR construct (Ghassemi et al., 2000).

In this study, we attempted to perform a comparative analysis of the effect of viable as well as heat-killed MAC on HIV replication. We have shown that MAC-induced enhancement of HIV-1 RT activity is mainly at the level of MAC infection, as heat-killed MAC failed to enhance HIV-1 RT activity significantly in a coinfection system. We have also shown enhanced HIV-induced, LTR-driven luciferase activity by viable MAC, confirming a significant increase in infectious virus production by viable MAC but not by heat-killed MAC. We have demonstrated further that heatkilled MAC induced HIV-1 LTR-directed CAT expression to a level similar to that of viable MAC. In addition, both viable and heat-killed MAC induced the DNA-binding activity of $\mathrm{NF}-\kappa \mathrm{B}$ to comparable levels. Taken together, these data suggest that MAC infection, and not simply exposure to $\mathrm{MAC}$ antigens, plays a significant role in the enhancement of HIV-1 replication in our coinfection model. In addition, this study confirms our previous findings that the induction of NF- $\kappa$ B-dependent LTR-CAT activity appears to account for only a small part of the effect of MAC on HIV upregulation (Ghassemi et al., 2000). Neither MAC-induced upregulation of cellular transcription factor NF- $\kappa$ B expression nor HIV-1 LTR-CAT expression appears to play a significant role in

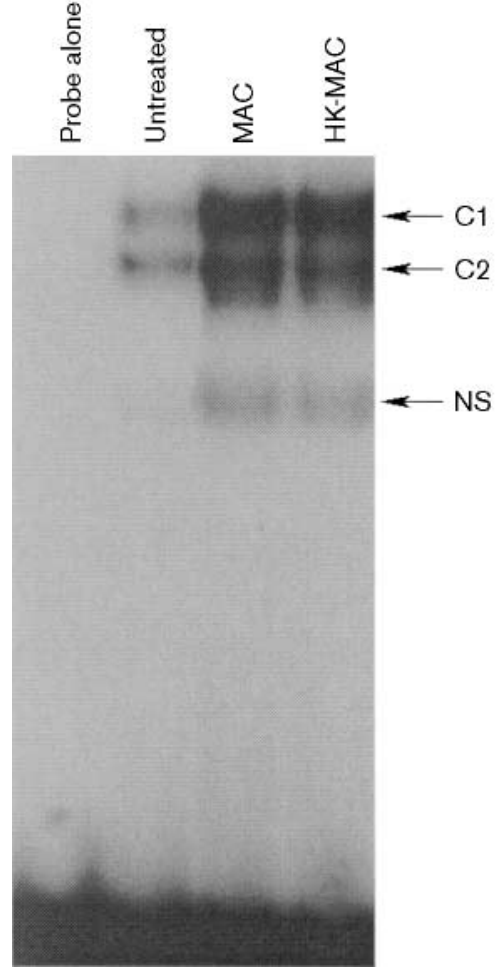

Fig. 5. Induction of NF- $\kappa \mathrm{B}$ DNA-binding activity by viable or heatkilled MAC. U937 cells were either left untreated or treated with viable or heat-killed MAC at $37{ }^{\circ} \mathrm{C}$ for $2 \mathrm{~h}$ and nuclear protein extracts were analysed for NF- $\kappa \mathrm{B}$ activity. The positions of the NF- $\kappa \mathrm{B}$ complexes (C1 and C2) and non-specific (NS) binding are indicated.

enhancing HIV replication in U937 cells coinfected with both pathogens. Rather, our findings suggest that viable MAC itself may produce or mediate the induction of an as-yetunidentified factor(s), which, in turn, enhances HIV replication.

Most reports published to date support the notion that mycobacteria accelerate the progression of HIV infection. However, using various experimental systems, conflicting results concerning the underlying mechanisms have been reported. Our work, as well as that of others, downplays the role of mycobacteria-induced soluble factors or NF- $\kappa \mathrm{B}$ dependent transcriptional activation in upregulating HIV expression (Shattock et al., 1993; 1994, Dezzutti et al., 1999; Ghassemi et al., 2000). Other studies, while reporting an enhancement of HIV p24/RT levels accompanied by cytokine secretion or cytokine-mediated NF- $\kappa$ B-dependent transcriptional activation, did not demonstrate fully a link between these events (Zhang et al., 1995; Goletti et al., 1996, 1998; Vanham et al., 1996). Mancino et al. (1997) have reported that viable but not heat-killed $M$. tuberculosis mediated an increase in HIV production in monocyte-derived macrophages, while Dezzutti et al. (1999) have shown that heat-killed and viable MAC enhanced the replication of lymphocytotropic HIV-1 strain LAI in CD8-depleted PBMCs to comparable levels. They have shown further that 
matrix metalloproteinases are involved in in vitro M. aviuminduced HIV-1 replication in CD8-depleted PBMCs, which are mainly independent of cytokine secretion (Dezzutti et al., 1999). In addition, other studies have shown that mycobacteria induce the chemokine receptor CCR5 (Wahl et al., 1998; Fraziano et al., 1999), which can potentially increase HIV infection, although the relationship between these in vitro observations and HIV pathogenesis in vivo has yet to be established.

Much work regarding mechanisms that regulate HIV replication has been conducted using the cell line $\mathrm{U} 1$, a subclone of U937 chronically infected with HIV (Folks et al., 1987, 1988). Lederman et al. (1994) have shown a comparable p24 antigen release in U1 cells with either live or heat-killed M. tuberculosis, which is consistent with our unpublished observations. Since electron microscopy studies in our institution as well as other centres (Lederman et al., 1994) failed to demonstrate any intracellular mycobacteria within $\mathrm{U} 1$ cells, it is apparent that these cells are not phagocytic for mycobacteria. Therefore, comparable amounts of mycobacteria-induced HIV activation in U1 cells by viable or heatkilled organisms appear to be due to exposure of cell membranes to intact mycobacteria or antigens and not to infection per se. This effect is partially mediated by mycobacteria-induced inflammatory cytokines (Lederman et al., 1994). In a similar study, phagocytosis of Salmonella typhimurium by $\mathrm{U} 1$ cells resulted in a 19-fold increase in HIV production, but heat-killed organisms could induce virus production by only 3 -fold (Andreana et al., 1994).

Phagocytes are capable of reacting differently to viable versus dead organisms and these particular responses are the ones exploited by HIV. A number of studies comparing live to heat-killed mycobacteria and other organisms have demonstrated relative differences in cell activation, which may prove to be relevant to HIV upregulation (Lovik \& Closs, 1984; Castro et al., 1991; Barker et al., 1997). Future efforts will focus on the differences in cell activation induced by live versus heat-killed organisms to understand further the role of mycobacterial infection in HIV upregulation.

In conclusion, this study, as well as our previous report that MAC-induced NF- $\kappa$ B mediates the enhancement of HIV-1 LTR-CAT transcription (Ghassemi et al., 2000), indicates that the induction of NF- $\kappa \mathrm{B}$ DNA-binding activity and/or the enhancement of HIV-1 LTR-CAT expression may not account for a significant part of the MAC effect on enhancement of HIV replication. It also suggests that in our coinfection model, the viability of MAC is important in mediating HIV upregulation.

\section{ACKNOWLEDGEMENTS}

This work was supported in part by the National Institutes of Health (R29, HHS HL57878-1) and the American Lung Association of Metropolitan Chicago.

\section{REFERENCES}

Andreana, A., Gollapudi, S., Kim, C. H. \& Gupta, S. (1994). Salmonella typhimurium activates human immunodeficiency virus type 1 in chronically infected promonocytic cells by inducing tumor necrosis factor- $\alpha$ production. Biochem Biophys Res Commun 201, 16-23.

Barker, L. P., George, K. M., Falkow, S. \& Small, P. L. (1997). Differential trafficking of live and dead Mycobacterium marinum organisms in macrophages. Infect Immun 65, 1497-1504.

Benson, C. (1994). Disseminated Mycobacterium avium complex disease in patients with AIDS. AIDS Res Hum Retroviruses 10, 913-916.

Castro, A. G., Esaguy, N., Macedo, P. M., Aguas, A. P. \& Silva, M. T. (1991). Live but not heat-killed mycobacteria cause rapid chemotaxis of large numbers of eosinophils in vivo and are ingested by the attracted granulocytes. Infect Immun 59, 3009-3014.

Chin, D. P., Reingold, A. L., Horsburgh, C. R., Jr \& 8 other authors (1994). Predicting Mycobacterium avium complex bacteremia in patients infected with human immunodeficiency virus: a prospectively validated model. Clin Infect Dis 19, 668-674.

Denis, M. \& Ghadirian, E. (1994). Interaction between Mycobacterium avium and human immunodeficiency virus type 1 (HIV-1) in bronchoalveolar macrophages of normal and HIV-1-infected subjects. Am J Respir Cell Mol Biol 11, 487-495.

Dezzutti, C. S., Swords, W. E., Guenthner, P. C. \& 7 other authors (1999). Involvement of matrix metalloproteinases in human immunodeficiency virus type 1-induced replication by clinical Mycobacterium avium isolates. J Infect Dis 180, 1142-1152.

Felber, B. K. \& Pavlakis, G. N. (1988). A quantitative bioassay for HIV-1 based on trans-activation. Science 239, 184-187.

Folks, T. M., Justement, J., Kinter, A., Dinarello, C. A. \& Fauci, A. S. (1987). Cytokine-induced expression of HIV-1 in a chronically infected promonocyte cell line. Science 238, 800-802.

Folks, T. M., Justement, J., Kinter, A., Schnittman, S., Orenstein, J., Poli, G. \& Fauci, A. S. (1988). Characterization of a promonocyte clone chronically infected with HIV and inducible by 13-phorbol-12myristate acetate. J Immunol 140, 1117-1122.

Fraziano, M., Cappelli, G., Santucci, M., Mariani, F., Amicosante, M., Casarini, M., Giosue, S., Bisetti, A. \& Colizzi, V. (1999). Expression of CCR5 is increased in human monocyte-derived macrophages and alveolar macrophages in the course of in vivo and in vitro Mycobacterium tuberculosis infection. AIDS Res Hum Retroviruses 15, 869-874.

Ghassemi, M., Andersen, B. R., Reddy, V. M., Gangadharam, P. R., Spear, G. T. \& Novak, R. M. (1995). Human immunodeficiency virus and Mycobacterium avium complex coinfection of monocytoid cells results in reciprocal enhancement of multiplication. J Infect Dis 171, $68-73$.

Ghassemi, M., Andersen, B. R., Roebuck, K. A., Rabbi, M. F., Plate, J. M. \& Novak, R. M. (1999). Mycobacterium avium complex activates nuclear factor $\kappa \mathrm{B}$ via induction of inflammatory cytokines. Cell Immunol 191, $117-123$.

Ghassemi, M., Asadi, F. K., Andersen, B. R. \& Novak, R. M. (2000). Mycobacterium avium induces HIV upregulation through mechanisms independent of cytokine induction. AIDS Res Hum Retroviruses 16, 435-440.

Goletti, D., Weissman, D., Jackson, R. W. \& 7 other authors (1996). Effect of Mycobacterium tuberculosis on HIV replication. Role of immune activation. J Immunol 157, 1271-1278.

Goletti, D., Weissman, D., Jackson, R. W., Collins, F., Kinter, A. \& Fauci, A. S. (1998). The in vitro induction of human immunodeficiency virus (HIV) replication in purified protein derivative-positive HIV-infected persons by recall antigen response to Mycobacterium tuberculosis is the 
result of a balance of the effects of endogenous interleukin-2 and proinflammatory and antiinflammatory cytokines. J Infect Dis 177, 1332-1338.

Horsburgh, C. R., Jr, Metchock, B., Gordon, S. M., Havlik, J. A., Jr, McGowan, J. E., Jr \& Thompson, S. E., III (1994). Predictors of survival in patients with AIDS and disseminated Mycobacterium avium complex disease. J Infect Dis 170, 573-577.

Lederman, M. M., Georges, D. L., Kusner, D. J., Mudido, P., Giam, C. Z. \& Toossi, Z. (1994). Mycobacterium tuberculosis and its purified protein derivative activate expression of the human immunodeficiency virus. J Acquir Immune Defic Syndr 7, 727-733.

Lee, M. H., Sano, K., Morales, F. E. \& Imagawa, D. T. (1987). Sensitive reverse transcriptase assay to detect and quantitate human immunodeficiency virus. J Clin Microbiol 25, 1717-1721.

Lovik, M. \& Closs, O. (1984). Induction of immunity against live Mycobacterium lepraemurium: a requirement for viable bacilli? Immunology 53, 165-173.

Mancino, G., Placido, R., Bach, S., Mariani, F., Montesano, C., Ercoli, L., Zembala, M. \& Colizzi, V. (1997). Infection of human monocytes with Mycobacterium tuberculosis enhances human immunodeficiency virus type 1 replication and transmission to $\mathrm{T}$ cells. J Infect Dis $\mathbf{1 7 5}$ $1531-1535$.

Nabel, G. \& Baltimore, D. (1987). An inducible transcription factor activates expression of human immunodeficiency virus in $\mathrm{T}$ cells. Nature 326, 711-713; erratum 344, 178.

Orenstein, J. M., Fox, C. \& Wahl, S. M. (1997). Macrophages as a source of HIV during opportunistic infections. Science 276, 1857-1861.

Schreiber, E., Matthias, P., Muller, M. M. \& Schaffner, W. (1989). Rapid detection of octamer binding proteins with 'mini-extracts', prepared from a small number of cells. Nucleic Acids Res 17, 6419.
Seed, B. \& Sheen, J. Y. (1988). A simple phase-extraction assay for chloramphenicol acyltransferase activity. Gene 67, 271-277.

Shattock, R. J., Friedland, J. S. \& Griffin, G. E. (1993). Modulation of HIV transcription in and release from human monocytic cells following phagocytosis of Mycobacterium tuberculosis. Res Virol 144, 7-12.

Shattock, R. J., Friedland, J. S. \& Griffin, G. E. (1994). Phagocytosis of Mycobacterium tuberculosis modulates human immunodeficiency virus replication in human monocytic cells. J Gen Virol 75, 849-856.

Spenlehauer, C., Gordon, C. A., Trkola, A. \& Moore, J. P. (2001). A luciferase-reporter gene-expressing T-cell line facilitates neutralization and drug-sensitivity assays that use either R5 or X4 strains of human immunodeficiency virus type 1. Virology 280, 292-300.

Vanham, G., Edmonds, K., Qing, L. \& 8 other authors (1996). Generalized immune activation in pulmonary tuberculosis: co-activation with HIV infection. Clin Exp Immunol 103, 30-34.

Wahl, S. M., Greenwell-Wild, T., Peng, G., Hale-Donze, H., Doherty, T. M., Mizel, D. \& Orenstein, J. M. (1998). Mycobacterium avium complex augments macrophage HIV-1 production and increases CCR5 expression. Proc Natl Acad Sci U S A 95, 12574-12579.

Wahl, S. M., Greenwell-Wild, T., Peng, G., Hale-Donze, H. \& Orenstein, J. M. (1999). Co-infection with opportunistic pathogens promotes human immunodeficiency virus type 1 infection in macrophages. J Infect Dis 179 (Suppl. 3), S457-S460.

Wahl, S. M., Greenwell-Wild, T., Hale-Donze, H., Moutsopoulos, N. \& Orenstein, J. M. (2000). Permissive factors for HIV-1 infection of macrophages. J Leukoc Biol 68, 303-310.

Zhang, Y., Nakata, K., Weiden, M. \& Rom, W. N. (1995). Mycobacterium tuberculosis enhances human immunodeficiency virus-1 replication by transcriptional activation at the long terminal repeat. J Clin Invest $\mathbf{9 5}$, $2324-2331$. 